\title{
Comparison of serum homocysteine level among preeclamptic and normotensive pregnant women: a case-control study in a tertiary care hospital
}

\author{
Kavya Ananthathirtha1, Pracheth Raghuveer ${ }^{2 *}$
}

\begin{abstract}
${ }^{1}$ Department of Obstetrics and Gynecology, KS Hegde Medical Academy, Nitte, Mangalore, Karnataka, India
${ }^{2}$ Department of Community Medicine, Yenepoya Medical College, Yenepoya, Mangalore, India
\end{abstract}

Received: 31 March 2019

Accepted: 08 April 2019

\section{*Correspondence:}

Dr. Pracheth Raghuveer,

E-mail: prach1986@gmail.com

Copyright: () the author(s), publisher and licensee Medip Academy. This is an open-access article distributed under the terms of the Creative Commons Attribution Non-Commercial License, which permits unrestricted non-commercial use, distribution, and reproduction in any medium, provided the original work is properly cited.

\begin{abstract}
Background: It has been postulated that hyperhomocysteinemia may be associated with preeclampsia, as the vascular changes mediated by homocysteine are similar to the changes that occur in preeclampsia. In this context, the study was conducted to compare maternal serum levels of total homocysteine in preeclamptic and normotensive pregnant women attending a tertiary care hospital in Coimbatore, Tamil Nadu, India.

Methods: A prospective case-control study was carried out in the inpatient wards and the outpatient department (OPD) of the Department of Obstetrics and Gynaecology (OBG) at a tertiary care hospital of Coimbatore, for one year from March 2015 to April 2016. Pregnant women with preeclampsia were considered as cases and women without any medical or other obstetric and fetal complications were selected as controls. A pre-designed and pretested proforma was used to collect the appropriate information. The assessments were conducted using standard procedures.

Results: The study population comprised of 50 cases and equal number of controls. Around $28.0 \%$ of the cases had severe preeclampsia. The mean serum homocysteine values among cases was $13.87 \pm 4.01 \mu \mathrm{mol} / \mathrm{L}$. The difference in the mean serum homocysteine level among cases and controls was statistically significant $(\mathrm{p}<0.001)$. However, there was no significant difference in the mean serum homocysteine levels among women with severe and mild preeclampsia $(\mathrm{p}=0.731)$.

Conclusions: Maternal serum levels of total homocysteine were found to be significantly higher among preeclamptic women when compared to normotensive women. Thus, estimation of serum homocysteine levels among preeclamptic women may serve as a biomarker for identifying those at risk for complications.
\end{abstract}

Keywords: Homocysteine, Pre-eclampsia, Pregnant women

\section{INTRODUCTION}

Preeclampsia (PE) is a multi-system pregnancy specific syndrome, which manifests by the onset of hypertension after 20 weeks of gestation in a previously normotensive pregnant woman and is believed to resolve with termination of pregnancy or by 12 weeks postpartum. As clinical presentation of $\mathrm{PE}$ is highly variable and even with severe disease a woman may be asymptomatic, the diagnosis is highly challenging. ${ }^{1}$ If there is no timely detection of PE, it can progress to multi-organ failure, coagulopathy, maternal and fetal death in its severe form. ${ }^{2}$ There are several predictors of PE, among which the evidence of high blood pressure values is the most 
reliable. Among bio-humoral parameters, homocysteine has recently been considered a possible remarkable cause of vascular damage. ${ }^{3}$ Hyperhomocysteinemia is considered as a risk factor for endothelial dysfunction and vascular disease such as atherosclerosis. Homocysteine mediated vascular changes are similar to those associated with PE and thus it has been hypothesized that hyperhomocysteinemia may be associated with PE. ${ }^{2}$ It was also found to be associated with placenta-mediated diseases such as placental abruption and may lead to miscarriage, IUGR, LBW, prematurity and congenital malformations.

There is a dearth of published literature which study the association between hyperhomocysteinemia and PE. Studies of such nature are required to plan appropriate interventions. In this context, author carried out to determine and compare the serum levels of total homocysteine among preeclamptic and normotensive pregnant women attending a tertiary care hospital in Coimbatore, Tamil Nadu, India and to find out the factors associated with high serum homocysteine among preeclamptic pregnant women.

\section{METHODS}

Author carried out a prospective case-control study in the inpatient wards and the OPD attached to the Department of OBG of G. Kuppuswamy Naidu Memorial (GKNM) Hospital, a tertiary care hospital for a period of one year from March 2015 to April 2016. The hospital has around 520 beds and is comprised of multiple specialties and allied services. The Department of OBG is regarded as the foremost tertiary referral centre for high risk pregnancy. The study population comprised of pregnant women with PE as cases and women without any medical or other obstetric and fetal complications as controls. Primigravida and multiparous pregnant women with gestational age between 20 to 40 weeks, with a diagnosis of $\mathrm{PE}$ by a $\mathrm{BP} \geq 140 \backslash 90 \mathrm{mmHg}$ on two or more occasions with or without proteinuria and imminent symptoms were included as cases, while age and gestational age matched normotensive pregnant women were selected as controls. Women who were sure of their gestational age (based on their last normal menstrual period or ultrasonography underwent in first or early second trimester) were included. Exclusion criteria included women with medical complications such as chronic hypertension, diabetes mellitus, liver and renal disorders, severe anaemia and obstetric complications such as abruptio placentae, pre-term labour and multiple pregnancy.

The sample size was calculated using the formula, $\mathrm{n}=$ $((Z \alpha / 2+Z \beta) 2 \times((\sigma 12+\sigma 22))) /($ Difference $) 2 .{ }^{4}$ Here, $\sigma 1$ refers to standard deviation (SD) of first group (4), $\sigma 2$ stands for SD of second group (5), $Z \alpha / 2$ is the desired level of statistical significance (typically 1.96) and $Z \beta$ is the desired power (typically 1.64 for $95 \%$ power). The mean homocysteine level among normotensive women, $\mu 1$ is taken as 17 , while the mean homocysteine level in preeclamptic women, $\mu 2$ is considered as 13.50 .5 The difference in the homocysteine levels among normotensive and preeclamptic women, $(\mu 1-\mu 2)=(17-$ $13.5)=3.5$. The effect size, " $d$ " is taken as 0.77 , while the probability of $\alpha$ error is set at 0.05 . The power of the study (1- $\beta$ error probability) is set at 0.95 , while the allocation ratio (N2/N1) for cases and controls is taken as 1. Using the above formula and on addition of $10 \%$ nonresponse rate, the total sample size is estimated to be 100 . Thus, a total of 50 study participants will be selected in each group, that is, the cases and controls. The number of preeclamptic women admitted in the inpatient ward of the Department of OBG, GKNM Hospital during the period of data collection were around 70, of which $9(12.86 \%)$ did not fulfil the inclusion criteria and $5(7.14 \%)$ refused to give consent for the study. Thus, in order to fulfil the sample size, the first 50 preeclamptic women admitted in the hospital during the period of data collection, were selected as cases and 50 normotensive women, who were matched with the cases for age and gestational age and admitted during the same period were selected as controls. Thus, purposive sampling was used to select the study participants.

Author carried out a face-to-face interview using a predesigned and pre-tested proforma. The proforma included information pertaining to the age, gestational age, obstetric score and the last menstrual period (LMP). The expected date of delivery (EDD) was calculated. Information regarding the marital history, menstrual history, significant past history, medical history, history of treatment taken for PE, presence of imminent symptoms was included in the proforma. A comprehensive general physical examination, systemic and obstetric examination was conducted. BP was measured using a Mercury Sphygmomanometer in the right arm, sitting position. ${ }^{6}$ The $\mathrm{BP}$ measurement was repeated after 6 hours and the highest reading of the two was entered in the proforma. The participant was asked to submit a random midstream urine sample and proteinuria was estimated using a spot urine dipstick method, using visual reagent strips, considered as a quick, portable, and easy to do method for analysis of proteinuria. ${ }^{7}$

Serum homocysteine was estimated on $2 \mathrm{ml}$ of serum by competitive chemiluminescent enzyme immunoassay method and the specimen was transported to the laboratory within 30 minutes of collection. ${ }^{8}$ Results were assured as per standard quality control regime. The normal values of serum homocysteine in pregnancy during second trimester is $2-26.9 \mu \mathrm{mol} / \mathrm{L}$, while it is $3.2-$ $21.4 \mu \mathrm{mol} / \mathrm{L}$ in third trimester. ${ }^{9}$

Approval from the institutional ethics committee was obtained before conducting the study. Detailed information pertaining to the nature, objectives of the study and test procedures was provided to the study participants and written informed consent was obtained. Anonymity of the study participants was ensured. Strict confidentiality of the information collected was 
maintained. Data was compiled and analyzed using the International Business Machine Statistical Package for Social Sciences (IBM SPSS) Statistics for Windows, Version 23.0 Armonk, New York: IBM Corp. Descriptive Statistics like means, standard deviations, percentages and proportions was applied for the purpose of distribution analysis. To find out the association between 2 continuous variables, like the differences in mean serum homocysteine and other parameters between the cases and controls, the normal distribution ' $Z$ ' Test was applied. Fischer's Exact test was applied to find out the association between two categorical variables. Multiple logistic regression analysis was conducted to control the confounders. Adjusted Odds Ratio (AOR) with 95\% Confidence Intervals (CI) were calculated. Statistical significance was set at a $\mathrm{p}$ value of $<0.05$.

\section{RESULTS}

A total of 55 women with PE were approach to participate in the study as cases, of which 5 refused to give consent to participate in the study. Thus, the present study yielded a non-response rate of $7.14 \%$. A total of 50 women with $\mathrm{PE}$ were selected as cases and 50 normotensive women whose age and gestational age matched with the cases were selected as controls.

The mean age among cases was $27.64 \pm 4.69$ years, while the mean age of controls was $27.52 \pm 4.11$ years. It was found that $36.0 \%$ of the preeclamptic antenatal women (cases) who took part in the study were $<30$ years of age, while $38.0 \%$ of the normotensive antenatal women (controls) were $<30$ years of age. Around $48(96.0 \%)$ and $2(4.0 \%)$ of the cases and controls were in the third (29. 40 weeks) and second trimester (13-28 weeks) respectively.
The mean gestational age of the study participants was $33.47 \pm 3.16$ weeks $(33.46 \pm 3.24$ weeks for cases and $33.45 \pm 3.14$ weeks for controls). More than half $(54.0 \%)$ of the cases were primigravidae, while $46.0 \%$ of the controls were primigravidae. The socio-demographic and clinical profile of the cases and controls are presented in Table 1.

Table 1: Socio-demographic and clinical profile of the study participants $(\mathrm{N}=100)$.

\begin{tabular}{|lll|}
\hline Variable & $\begin{array}{l}\text { Cases }(\mathrm{n}=50) \\
\text { with } \%\end{array}$ & $\begin{array}{l}\text { Controls }(\mathrm{n}=50) \\
\text { with } \%\end{array}$ \\
\hline Age in years & & \\
\hline$<30$ years & $18(36.0 \%)$ & $19(38.0 \%)$ \\
\hline$>30$ years & $32(64.0 \%)$ & $31(62.0 \%)$ \\
\hline Booked & & \\
\hline At GKNM hospital & $17(34.0 \%)$ & $49(98.0 \%)$ \\
\hline Other hospital & $33(66.0 \%)$ & $1(2.0 \%)$ \\
\hline Gravidity & & \\
\hline Primigravidae & $27(54.0 \%)$ & $23(46.0 \%)$ \\
\hline Multigravidae & $23(46.0 \%)$ & $27(54.0 \%)$ \\
\hline
\end{tabular}

A high proportion of cases, 35 (70.0\%), had a BP ranging from $\geq 140 / 90 \mathrm{~mm}$ of $\mathrm{Hg}$ to $<160 / 110 \mathrm{~mm}$ of $\mathrm{Hg}$, while $14(28.0 \%)$ had a BP of $\geq 160 / 110 \mathrm{~mm}$ of $\mathrm{Hg}$ and 1 (2.0\%) had a BP of $<140 / 90 \mathrm{~mm}$ of $\mathrm{Hg}$. It was also found that $13(26.0 \%)$ of the cases had imminent symptoms and signs. Among cases, the grading of proteinuria with proportions and percentages were as follows- $1+: 19$ (38.0\%), 2+:17 (34.0\%), 3+:12(24.0\%) and 4+:2 (4.0\%) while among controls $46(92.0 \%)$ had no proteinuria. However, $4(8.0 \%)$ of the controls had a proteinuria of $1+$.

Table 2: Comparison of serum homocysteine levels between cases and controls $(\mathrm{N}=100)$.

\begin{tabular}{|lllllll|}
\hline \multirow{2}{*}{ Pair } & \multicolumn{2}{l}{ Paired differences } & & & & \\
& Mean difference & SD & Standard error of mean & $\mathbf{9 5 \%}$ CI of difference & t* & P \\
\hline Serum homocysteine & 5.36 & 4.39 & 0.62 & $4.11-6.60$ & 8.635 & $<0.001^{\dagger}$ \\
\hline
\end{tabular}

*Paired t-test, $\uparrow$ Statistically significant $(\mathrm{p}<0.05)$.

The mean serum homocysteine values were $13.87 \pm 4.01$ $\mu \mathrm{mol} / \mathrm{L}$. The minimum serum homcysteine value among cases was $9.6 \mu \mathrm{mol} / \mathrm{L}$, while the maximum value was $26.4 \mu \mathrm{mol} / \mathrm{L}$. The average serum homocysteine levels among controls was found to be $8.51 \pm 2.25 \mu \mathrm{mol} / \mathrm{L}$ (minimum- $4.5 \mu \mathrm{mol} / \mathrm{L}$, maximum- $15.1 \mu \mathrm{mol} / \mathrm{L}$ ). Serum homocysteine was further categorized into 'high' (>21.4 $\mu \mathrm{mol} / \mathrm{L}$ if in third trimester and $>26.9 \mu \mathrm{mol} / \mathrm{L}$ in case of second trimester cases) and 'normal' (within the prescribed normal range in pregnancy). ${ }^{3,6}$ It was observed that a sizeable majority, 47 (94.0\%), had serum homcocysteine levels within normal limits, while 3
(6.0\%) had high Serum homocysteine. The difference in the mean serum homocysteine level between cases and controls $(13.87-8.51=5.36)$ was found to be statistically significant $(\mathrm{t}=8.635, \mathrm{p}<0.001)$. This comparison is presented in Table 2.

Fischer's Exact test was applied to find out the association between the serum homocysteine levels in preeclamptic women with the socio-demographic and clinical variables (Table 3). However, none of the associations were statistically significant. Further, it was found that those preeclamptic women having a BP of 
$>160 / 110 \mathrm{mmHg}$ had 1.308 odds for high Serum Homocysteine $\quad(\mathrm{AOR}=1.308,95 \% \quad \mathrm{CI}=0.109-15.679)$.
This relationship was not statistically significant $(\mathrm{p}=0.832)($ Table 4).

Table 3: Association of the socio-demographic and variables with serum homocysteine levels among cases ( $\mathrm{N}=50$ ).

\begin{tabular}{|c|c|c|c|c|}
\hline Variables & $\begin{array}{l}\text { High serum homocysteine } \\
(\mathrm{n}=\mathbf{3})(\%)\end{array}$ & $\begin{array}{l}\text { Normal serum homocysteine } \\
(\mathrm{n}=47)(\%)\end{array}$ & Total & P value* \\
\hline \multicolumn{5}{|c|}{ 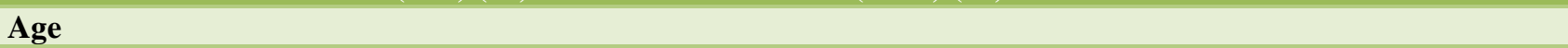 } \\
\hline$<30$ years & $1(5.60 \%)$ & 17 (94.40\%) & 18 & \multirow{2}{*}{0.709} \\
\hline$\geq 30$ years & $2(6.30 \%)$ & $30(93.80 \%)$ & 32 & \\
\hline \multicolumn{5}{|l|}{ Gestational age } \\
\hline Second trimester & $3(6.30 \%)$ & $45(93.80 \%)$ & 48 & \multirow{2}{*}{0.3076} \\
\hline Third trimester & $0(0)$ & $2(100.0 \%)$ & 2 & \\
\hline \multicolumn{4}{|l|}{ Gravidity } & \multirow{3}{*}{0.2982} \\
\hline Primigravidae & $1(3.70 \%)$ & $26(96.30 \%)$ & 27 & \\
\hline Multigravidae & $2(8.70 \%)$ & $21(91.30 \%)$ & 23 & \\
\hline \multicolumn{4}{|l|}{ Imminent signs } & \multirow{3}{*}{0.604} \\
\hline Present & $1(7.70 \%)$ & $12(92.90 \%)$ & 13 & \\
\hline Absent & $2(5.40 \%)$ & $35(94.60 \%)$ & 37 & \\
\hline
\end{tabular}

*Fischer's Exact test.

Table 4: Confounder-adjusted covariates of high serum homocysteine among cases $(\mathbf{n}=50)$.

\begin{tabular}{|lllc|}
\hline Variables & AOR* & CI* & P value \\
\hline Age in years & & $0.074-10.464$ & 0.921 \\
\hline$\geq 30$ years & 0.882 & $0.034-4.767$ & 0.472 \\
\hline$<30$ years & Reference & & \\
\hline Gravidity & & \multirow{2}{*}{$0.121-17.561$} & 0.766 \\
\hline Primigravida & 0.404 & & \\
\hline Multigravida & Reference & & $0.109-15.679$ \\
\hline Imminent signs & 1.458 & 0.832 \\
\hline Present & Reference & & \\
\hline Absent & & & \\
\hline BP & 1.308 & & \\
\hline$\geq 160 / 110 \mathrm{~mm}$ of $\mathrm{Hg}$ & Reference & & \\
\hline$<160 / 110 \mathrm{~mm}$ of $\mathrm{Hg}$ & & & \\
\hline *Multiple logistic regression & & & \\
\hline
\end{tabular}

*Multiple logistic regression.

\section{DISCUSSION}

Author carried out this study to compare the serum levels of total homocysteine in preeclamptic and normotensive pregnant women. The present study included 50 preeclamptic women fulfilling the inclusion criteria as cases and 50 age and gestational age matched normotensive women as controls. It was observed that $72.0 \%$ of the preeclamptic women had a BP of $<160 / 110$ $\mathrm{mm}$ of $\mathrm{Hg}$, while $28.0 \%$ had severe $\mathrm{PE}$, with a BP of $\geq 160 / 110 \mathrm{~mm}$ of $\mathrm{Hg}$. The mean serum homocysteine levels were found to be significantly higher among the preeclamptic women when compared to the normotensive women ( $\mathrm{p}<0.001)$. Preeclamptic women with a BP of $\geq 160 / 110 \mathrm{~mm}$ of $\mathrm{Hg}$ had 1.307 odds for high serum homocysteine when compared to preeclamptic women with a $\mathrm{BP}$ of $<160 / 110 \mathrm{~mm}$ of $\mathrm{Hg}(\mathrm{AOR}=1.307,95 \%$ $\mathrm{CI}=0.109-15.679, \mathrm{p}=0.832$ ).

Homocysteine is an amino acid which has gained prominence in the recent years. ${ }^{10}$ The mean homocysteine levels normally decrease with gestation either due to physiological response to the pregnancy, increase in estrogen, hemodilution from increased plasma volume or increased demand for methionine by both the mother and fetus. ${ }^{11}$ However, it is known to be an offending factor in the vascular pathology causing PE. ${ }^{12}$ Storkova V et al, have reported that homocysteinemia is an important independent cardiovascular risk factor, which might induce the endothelial dysfunction observed in preeclampsia. ${ }^{13}$ Likewise, the role of elevated Serum Homocysteine in PE has been explored by several researchers in the past. $^{2,14-19}$ 
In the present study, a significant difference was found between the mean serum homocysteine levels of preeclamptic women and normotensive women ( $p$ $<0.001)$. The results of a research carried out by Wadhwani NS et al, in Pune in the year 2015 was in concordance with this finding. ${ }^{20}$ This finding was also similar to the result of a study carried out by Sangeetha $\mathrm{N}$ et al, in New Delhi and Sanlikan F et al, in Poland. ${ }^{11,14}$ On the contrary, D' Anna R et al, who conducted a study in a cohort of 1874 pregnant women, didn't report a statistically significant difference in the mean homocysteine among women with $\mathrm{PE}$ and normotensive controls. $^{21}$

The present study gives valuable information regarding the association between elevated serum homocysteine and PE. The merits of this study include the fact that appropriate methodology was followed with the controls being matched with the cases to eliminate any potential bias due to confounding. The present study also gives confounder-adjusted estimates. However, the results of this study need to be interpreted with caution, as the study has a few limitations. Serum for homocysteine levels could not be collected in eclamptic women because of the emergency need to terminate the pregnancy. Serum homocysteine levels could not be measured at intervals to assess the response to anti-hypertensives owing to financial constraints. Despite these drawbacks, the findings of this study may provide valuable inputs to clinicians in managing PE.

\section{CONCLUSION}

Present study concludes that preeclamptic women have a significantly higher serum homocysteine when compared to normotensive women. Thus, the findings of this study stress that elevated serum homcysteine has a definite role to play in PE.

\section{ACKNOWLEDGMENTS}

Authors would like to thank participants, Department of OBG, GKNM Hospital, Coimbatore, India for their support during study.

Funding: No funding sources

Conflict of interest: None declared

Ethical approval: The study was approved by the Institutional Ethics Committee

\section{REFERENCES}

1. Duhig KE, Shennan AH. Recent advances in the diagnosis and management of pre-eclampsia. F1000 Prime Rep. 2015;7.

2. Ingec M, Borekci B, Kadanali S. Elevated plasma homocysteine concentrations in severe preeclampsia and eclampsia. Tohoku J Exp Med. 2005;206(3):22531.
3. Noto R, Neri S, Noto Z, Cilio D, Abate G, Noto P, et al. Hyperhomocysteinemia in preeclampsia is associated to higher risk pressure profiles. Euro Rev Med Pharmacol Sci. 2003;7:81-7.

4. Dissertation Statistics. Samples and Sample Size. Available at: http://www.dissertationstatistics.com/samples-sample-size.html. Accessed 2019 Mar 15.

5. Ghike S, Jain S, Kumare B, Gupta M, Shembedkar C. A study of serum homocysteine levels during normal pregnancy and pre-eclampsia. J South Asian Federation Obstetrics Gynaecol. 2011;3(2):71-4.

6. Pickering TG, Hall JE, Appel LJ. Recommendations for blood pressure measurement in humans and experimental animals: Part 1: blood pressure measurement in humans: a statement for professionals from the Subcommittee of Professional and Public Education of the American Heart. Association Council on High Blood Pressure Research. Hypertension. 2005;45:142.

7. Waugh JJS, Bell SC, Kilby MD, Blackwell CN, Seed $\mathrm{P}$, Shennan AH, et al. Optimal bedside analysis for the detection of proteinuria in hypertensive pregnancy: a study of diagnostic accuracy. $\mathrm{Br} \mathrm{J}$ Obstet Gynaecol. 2005;112:412-7.

8. Ueland PM, Refsum H, Stabler SP, Malinow MR, Andersson A, Allen RH. Total homocysteine in plasma or serum: methods and clinical applications. Clin Chem. 1993; 39:1764-79.

9. Abbassi-Ghanavati M, Greer LG, Cunningham FG. Pregnancy and laboratory studies: a reference table for clinicians. Obstet Gynecol. 2009;114(6):1326-31.

10. Forges T, Monnier-Barbarino P, Alberto JM, Gu'eant-Rodriguez RM, Daval JL, Gu'eant JL. Impact of folate and homocysteine metabolism on human reproductive health. Human Reproduction Update. 2007;13(3):225-38.

11. Sangeeta N, Shaini L, Basar G, Soni Devi, Chhuangi V, Mandal KK, et al. Serum Uric Acid and Homocysteine as Predictors of Pre-eclampsia. J Diabetes Metab. 2013;4:259.

12. Patel AP, Chakrabarti C, Singh A, Patel JD, Mewada HA, Sharma SL. Effect of Homocysteine, Vitamin B12, Folic acid during pregnancy. NHL J Med Sci. 2012;1(1):27-31.

13. Stoikova V, Ivanov S, Mazneikova V, Tsoncheva A. Serum homocysteine levels in pregnant women with preeclampsia. Akush Ginekol (Sofiia). 2005;44(6):16-9.

14. Sanlikan F, Tufan F, Gocmen A, Kabadayi C, Senqui E. The evaluation of homocysteine level in patients with preeclampsia. Ginekol Pol. 2015;86(4):287-91.

15. Yanez P, Vasques CJ, Rodas L, Duran A, Chedraui $\mathrm{P}$, Liem KH, et al. Erythrocyte folate content and serum folic acid and homocysteine levels in preeclamptic primigravidae teenagers living at high altitude. Arch Gynecol Obstet. 2013;288(5):1011-5.

16. Acilmis YG, Dikensoy E, Kutlar AI, Balat O, Cebesoy FB, Ozturk E, et al. Homocysteine, folic acid and vitamin B12 levels in maternal and 
umbilical cord plasma and homocysteine levels in placenta in pregnant women with pre-eclampsia. J Obstetrics Gynaecol Res. 2011;37:45-50.

17. Atis A, Aydin Y, Basol E, Goker N. Troponin I and homocysteine levels in mild and severe preeclampsia. Clin Exp Obstet Gynecol. 2010;37(1):21-3.

18. Makedos G, Papanicolaou A, Hitoglou A, Kalogiannidis L, Makedos A, Vrazioti V et al. Homocysteine, folic acid and B12 serum levels in pregnancy complicated with preeclampsia. Arch Gynecol Obstet. 2007;275(2):121-4.

19. Braekke K, Ueland PM, Harsem NK, Karlsen A, Blomhoff R, Staff AC. Homocysteine, cysteine, and related metabolites in maternal and fetal plasma in preeclampsia. Pediatr Res. 2007;62(3):319-24.

20. Wadhwani NS, Patil VV, Mehendale SS, Wagh GN, Gupte SA, Joshi SR. Increased homocysteine levels exist in women with preeclampsia from early pregnancy. J Matern Fetal Neonatal Med. 2016;29(16):2719-25.

21. D'Anna R, Baviera G, Corrado F, Ientile R, Granese D, Stella NC. Plasma homocysteine in early and late pregnancies complicated with preeclampsia and isolated intrauterine growth restriction. Acta Obstet Gynecol Scand. 2004;83(2):155-8.

Cite this article as: Ananthathirtha K, Raghuveer P. Comparison of serum homocysteine level among preeclamptic and normotensive pregnant women: a case-control study in a tertiary care hospital. Int J Reprod Contracept Obstet Gynecol 2019;8:1784-9. 